\title{
The Relationship between Hardness and Wear of Alloys in Liquid Nitrogen*
}

\author{
By Byong Sun CHUN** and Hajime SUTO**
}

\begin{abstract}
Synopsis
The tests of rubbing wear against hardened $0.45 \% \mathrm{C}$-steel and 316type austenitic stainless steel were carried out in liquid $\mathrm{N}_{2}$. Specimens used are (a) $20 \% \mathrm{Cr}-(\mathrm{Fe}, \mathrm{Co}, \mathrm{Ni})$ solid solution alloys, $(b)$ age-hardenable Nimonic 80A and Nimonic 100 alloys, and (c) low-Gr martensitic steels with and without carbide dispersion, whose martensite matrixes were controlled to have about $0.45 \% \mathrm{C}$. The rolling contact fatigue in liq. $\mathrm{N}_{2}$ of these low-Cr steels were also investigated. The results obtained are as follows.

(1) The harder the solid solution is the fewer the wear-loss is. When the difference in hardness between the coupled specimens is large, the softer material adheres on the surface of the harder specimen, and then the coefficient of friction is very large.

(2) Age-hardening increases the wear-proof of the alloy.

(3) The rubbing pair of matensitic steels is abrasively worn. The wear is suppressed by carbide dispersion, but the effect of the amount of carbide on wear is not so distinct. The rolling contact fatigue strength is increased by carbide dispersion.

(4) It is considered roughly that the soft and ductile materials are adhesively worn, tough materials are worn by delamination process, and the hard and brittle materials are abrasively worn. However, multiple processes proceed simultaneously, and the contribution of each process changes with the wearing conditions. Therefore, the relation between hardness and wear is sometimes complicated.
\end{abstract}

\section{Introduction}

The low temperature liquidized gases are widely used in various industries nowadays. The suitable materials for some machine parts subjected to sliding friction in liquidized gases must be selected from the view points of hardness and wear-proof under the operating conditions. The papers on wear are innumerable, but almost all these experiments were carried out at R.T. or at elevated temperatures. It must be emphasized that the wear in liquidized gases such as $\mathrm{N}_{2}$ or $\mathrm{H}_{2}$ proceeds under the special conditions of air-sealed and chilled lubrication of the liquidized gases. Therefore, the behaviour of wear in liquidized gases should be different from those in ambient conditions. In the previous papers ${ }^{1,2}$ ) on wear of several kinds of FCG alloys against a 0.45 $\% \mathrm{C}$ martensitic steel and a SUS316 type stainless steel in liq. $\mathrm{N}_{2}$, the authors have pointed out that the harder alloys were rather the more wear-proof, but the data scattered and the wear-loss of alloys containing large second phase particles was increased by age hardening. In the present work, the rubbing wear in liq. $\mathrm{N}_{2}$ of alloys having various microstructures and hardness of wide range was examined systematically and the relation between hardness and wear is newly discussed. For the common companions against these specimens for wear tests, quench-hardened 0.45 $\%$ C-steels (S45C) and 316-type austenitic stainless steels (SUS316) were selected as a typical hard material and a ductile one.

\section{Experimental Procedure}

The alloys used are classified into three groups;

(a) FCC solid solution alloys, $20 \% \mathrm{Cr}-(\mathrm{Fe}, \mathrm{Co}, \mathrm{Ni})$,

(b) FGC age-hardenable alloys, Nimonic $80 \mathrm{~A}$ and Nimonic 100, and

(c) medium and high carbon low chromium steels. The chemical composition of the groups (a) and (b) including S45C and SUS316 are shown in Table 1. In consideration of that in the previous work, ${ }^{2)}$ the relation between hardness and wear complicated by large residual second phase particles in A286 and S816 alloys used, the Nimonic alloys in the present work were prepared and quenched from high temperatures enough for perfect solutioning. The conditions of heat treatment for these specimens and the hardness at R.T., $-119^{\circ} \mathrm{C}$ (in liq. $\mathrm{O}_{2}$ ) and $-196^{\circ} \mathrm{C}$ (liq. $\mathrm{N}_{2}$ ) are shown in Table 2. The chemical composition of the group (c) steels are shown in Table 3. These steels were prepared to have structures containing various amounts of dispersed carbide particles in the martensitic matrix of a given composition, ${ }^{3)}$ in order to study the effect of dispersed carbide particles on the rubbing wear and rolling contact fatigue life. The " TX-14C" steel corresponds to a typical bearing steel (SUJ-2). These low-Cr steels were subjected to spheroidization as shown in Table 4 and followed by quench and temper according to the schedules shown in Table 5 so that martensites phase becomes to contain $0.45 \%$ C. The hardness of all these specimens including S45C steel was controlled to be about Hv785 as shown in Table 5. The structure of "TX-8M" steel is carbide free martensite, and the contents of residual carbide in "TX-12G", "TX-13G" and "TX-14G" steels are 6.42, 8.02 and 8.09 vol\%, respectively. The carbon contents of martensitic matrix in these steels were determined metallographically to be $0.48 \%$ for " TX-12G" and "TX-13C" and $0.47 \%$ for " TX-14C".

Cylindrical specimens, whose outside diameter was $20 \mathrm{~mm}$ and inside diameter was $16 \mathrm{~mm}$, were prepared for sliding wear test. The edge planes of 113 $\mathrm{mm}^{2}$ were polished and cleaned. A couple of specimens was set in the wear test machine ${ }^{1,2)}$ and dipped in liq. $\mathrm{N}_{2}$. The upper specimen of the couple was

\footnotetext{
* Presented to the Committee on Wear of Iron and Steel Products, Joint Society on Iron and Steel Basic Research, April 1982. Manuscript received August 20, 1982. (C) 1983 ISIJ

** Department of Materials Science, Faculty of Engineering, Tohoku University, Aramaki Aoba, Sendai 980.
} 
Table 1. Chemical composition of specimens used. (mass\%)

\begin{tabular}{l|c|cccccccccccc}
\hline \multicolumn{1}{c|}{ Alloy } & Symbol & G & Si & Mn & P & S & Ni & Cr & Mo & Ti & Al & Fe & Go \\
\hline 40Ni-40Fe-20Cr & $40 \mathrm{~N}$ & 0.006 & 0.02 & 0.68 & - & 0.008 & 39.28 & 20.12 & - & - & - & bal. & - \\
80Ni-20Cr & $80 \mathrm{~N}$ & 0.005 & - & 0.61 & - & 0.004 & 80.84 & 19.54 & - & - & - & - & - \\
20Ni-60Co-20Cr & $20 \mathrm{~N}$ & 0.009 & - & - & - & 0.007 & 20.52 & 19.41 & - & - & - & - & bal. \\
Nimonic 80A & N8 & 0.109 & 0.47 & 0.62 & - & 0.004 & bal. & 18.71 & - & - & 1.90 & 4.41 & 20.50 \\
Nimonic 100 & N1 & 0.155 & 0.39 & - & - & 0.002 & bal. & 9.38 & 4.14 & - & - & 2.10 & 20.50 \\
SUS316 & S & 0.06 & 0.56 & 1.57 & 0.029 & 0.019 & 10.88 & 17.08 & 2.30 & - & - & bal. & - \\
S45C & S' & 0.44 & 0.22 & 0.71 & 0.017 & 0.019 & 0.04 & 0.07 & 0.024 & 0.01 & - & - & - \\
\hline
\end{tabular}

Table 2. Heat treatment and hardness. ( $H v: 10 \mathrm{kgf}$ )

\begin{tabular}{|c|c|c|c|c|c|c|c|}
\hline \multirow{3}{*}{ Alloy } & \multicolumn{4}{|c|}{ As quenched } & \multicolumn{3}{|c|}{ Age hardened } \\
\hline & \multirow{2}{*}{ Heat treatment } & \multicolumn{3}{|c|}{$H v$} & \multirow{2}{*}{ Heat treatment } & \multicolumn{2}{|c|}{$H v$} \\
\hline & & $R . T$. & liq. $\mathrm{O}_{2}$ & liq. $\mathrm{N}_{2}$ & & $R . T$. & liq. $\mathrm{N}_{2}$ \\
\hline $40 \mathrm{~N}$ & $880^{\circ} \mathrm{C} \times 2 \mathrm{~h} / F . C$ & 146 & & 166 & & & \\
\hline $80 \mathrm{~N}$ & $880^{\circ} \mathrm{C} \times 2 \mathrm{~h} / F . C$ & 168 & & 177 & & & \\
\hline $20 \mathrm{~N}$ & $880^{\circ} \mathrm{C} \times 2 \mathrm{~h} / F . C$ & 270 & & 281 & & & \\
\hline N8 & $1200^{\circ} \mathrm{C} \times 2 \mathrm{~h} / W \cdot Q$ & 193 & & 208 & $704^{\circ} \mathrm{C} \times 256 \mathrm{~h} / A . C$ & 408 & 415 \\
\hline $\mathrm{N} 1$ & $1280^{\circ} \mathrm{C} \times 5 \mathrm{~h} / W \cdot Q$ & 266 & & 274 & $704^{\circ} \mathrm{G} \times 256 \mathrm{~h} / A . C$ & 434 & 443 \\
\hline $\mathrm{S}$ & $1060^{\circ} \mathrm{C} \times 1.2 \mathrm{~h} / W \cdot Q$ & 205 & 312 & 333 & & & \\
\hline $\mathrm{S}^{\prime}$ & $830^{\circ} \mathrm{C} \times 1 \mathrm{~h} / W \cdot Q$ & 708 & 851 & 858 & & & \\
\hline
\end{tabular}

Table 3. Chemical composition of low-Cr steels used. (mass\%)

\begin{tabular}{c|cccccccccccc}
\hline Steel & $\mathrm{G}$ & $\mathrm{Si}$ & $\mathrm{Mn}$ & $\mathrm{P}$ & $\mathrm{S}$ & $\mathrm{Cu}$ & $\mathrm{Ni}$ & $\mathrm{Cr}$ & $\mathrm{Ti} . \mathrm{Al}$ & $\mathrm{Sn}$ & $\mathrm{As}$ & $\mathrm{Fe}$ \\
\hline TX-8M & 0.47 & 0.16 & 0.35 & 0.017 & 0.008 & 0.12 & 0.07 & 0.72 & 0.022 & 0.028 & 0.028 & bal. \\
TX-12C & 0.87 & 0.20 & 0.27 & 0.015 & 0.009 & 0.11 & 0.07 & 1.33 & 0.023 & 0.031 & 0.036 & bal. \\
TX-13C & 1.00 & 0.18 & 0.28 & 0.021 & 0.006 & 0.13 & 0.08 & 1.49 & 0.023 & 0.022 & 0.039 & bal. \\
TX-14C & 1.08 & 0.20 & 0.20 & 0.018 & 0.008 & 0.12 & 0.07 & 1.53 & 0.017 & - & - & bal. \\
\hline
\end{tabular}

Table 4. Spheroidizing heat treatment of low-Cr steels used.

\begin{tabular}{|c|c|c|c|c|c|c|c|c|}
\hline TX-8M & $880^{\circ} \mathrm{C} / 1 \mathrm{~h}$ & $\rightarrow$ & $W \cdot Q \rightarrow$ & $700^{\circ} \mathrm{C} / 12 \mathrm{~h} \rightarrow$ & $\left(720^{\circ} \mathrm{C} / 15 \mathrm{~min}\right.$ & $10^{\circ} \mathrm{C} / \mathrm{h}$ & $\left.650^{\circ} \mathrm{C} / 15 \mathrm{~min}\right) \times 3 \rightarrow$ & $\rightarrow \quad F . G$ \\
\hline $\mathrm{TX}-12 \mathrm{C}$ & $930^{\circ} \mathrm{C} / 3 \mathrm{~h}$ & $\rightarrow$ & $A . G \rightarrow$ & $770^{\circ} \mathrm{C} / 3 \mathrm{~h} \rightarrow$ & $880^{\circ} \mathrm{C} / 16 \mathrm{~h}$ & $10^{\circ} \mathrm{C} / \mathrm{h}$ & $680^{\circ} \mathrm{C}$ & $\rightarrow \quad F . C$ \\
\hline $\mathrm{TX}-13 \mathrm{C}$ & $930^{\circ} \mathrm{C} / 3 \mathrm{~h}$ & $\rightarrow$ & $A . C \rightarrow$ & $770^{\circ} \mathrm{C} / 3 \mathrm{~h} \rightarrow$ & $800^{\circ} \mathrm{C} / 16 \mathrm{~h}$ & $10^{\circ} \mathrm{C} / \mathrm{h}$ & $680^{\circ} \mathrm{C} \longrightarrow$ & $F . G$ \\
\hline TX-14G & $950^{\circ} \mathrm{C} / 3 \mathrm{~h}$ & $\rightarrow$ & $A . G \rightarrow$ & $780^{\circ} \mathrm{C} / 3 \mathrm{~h} \rightarrow$ & $820^{\circ} \mathrm{C} / 16 \mathrm{~h}$ & $10^{\circ} \mathrm{C} / \mathrm{h}$ & $\longrightarrow$ & F.C \\
\hline
\end{tabular}

$W . Q$ : water quench, A.C: air cool, $F . C:$ furnace cool

Table 5. Heat treatment and hardness of low-Cr steels used.

\begin{tabular}{|c|c|c|c|}
\hline \multirow{2}{*}{$\begin{array}{l}\vec{\Xi} \\
\stackrel{\Xi}{\omega}\end{array}$} & \multirow{2}{*}{\multicolumn{2}{|c|}{ Quenching and tempering }} & $\begin{array}{c}H v \\
(10 \mathrm{kgf})\end{array}$ \\
\hline & & & $R . T . \stackrel{\text { liq. }}{\mathrm{N}_{2}}$ \\
\hline $\begin{array}{l}\text { TX- } \\
8 \mathrm{M}\end{array}$ & $880^{\circ} \mathrm{G} \times 1 \mathrm{~h} / W \cdot Q$ & $150^{\circ} \mathrm{C} \times 90 \mathrm{~min} / W \cdot Q$ & $783 \quad 882$ \\
\hline $\begin{array}{l}\mathrm{TX}- \\
12 \mathrm{C}\end{array}$ & $840^{\circ} \mathrm{C} \times 25 \mathrm{~min} / W . Q$ & $150^{\circ} \mathrm{G} \times 90 \mathrm{~min} / W \cdot Q$ & $783 \quad 882$ \\
\hline $\begin{array}{l}\text { TX- } \\
13 \mathrm{C}\end{array}$ & $825^{\circ} \mathrm{G} \times 25 \mathrm{~min} / W . Q$ & $150^{\circ} \mathrm{G} \times 90 \mathrm{~min} / W . Q$ & $792 \quad 894$ \\
\hline $\begin{array}{l}\text { TX- } \\
14 \mathrm{C}\end{array}$ & $820^{\circ} \mathrm{C} \times 25 \mathrm{~min} / W \cdot Q$ & $150^{\circ} \mathrm{G} \times 90 \mathrm{~min} / W . Q$ & $792 \quad 882$ \\
\hline
\end{tabular}

rotated for $10 \mathrm{~min}$ under the load of 5.2 to $11.2 \mathrm{kgf}$. The wear speed was $20.3 \mathrm{~m} / \mathrm{min}$ and the wear distance was $203.4 \mathrm{~m}$. The wear loss is expressed in the unit of $\mathrm{mg} / 113 \mathrm{~mm}^{2}$.

One of the authors ${ }^{3}$ ) conducted rolling contact fatigue tests at R.T. for the steels shown in Table 3, and obtained the result that fatigue life of martensite was extended by dispersed carbide particles. In the present work, the testing machine was modified so that both the specimen and rolling balls could be dipped in liq. $\mathrm{N}_{2}$. The diameter and the thickness of the specimen are $50 \mathrm{~mm}$ and $5 \mathrm{~mm}$, respectively. Three SUJ-2 balls of $6.3 \mathrm{~mm}$ in diameter were rolled on the test specimen under the load of $1000 \mathrm{kgf}$. 
The rolling track was $23.5 \mathrm{~mm}$ in diameter, and the frequency of stressing was $15 \mathrm{~Hz}$. The starting point of flaking was detected by the rolling noise.

\section{Results}

Figure 1 shows the wear curves for four kinds of solid solutions, " $40 \mathrm{~N} "$, " $80 \mathrm{~N}$ " and " $20 \mathrm{~N} " 20 \% \mathrm{Cr}$ steels and SUS316 rubbed in liq. $\mathrm{N}_{2}$ against S45C specimens. The symbol with a slash mark on each curve indicates the material for which the weight loss over the companion material was measured. It was found that the weight-loss increased in the reverse order of hardness. The present results show a similar tendency to the Suh's results ${ }^{4)}$ that the weight-loss of copper alloys rubbed in Ar-atmosphere at R.T. against SUJ-2 companions decreased with increasing the concentration of alloying elements.

The coefficient of friction between SUS316 and $\mathrm{S} 45 \mathrm{C}$ is less than 0.5 . This value is virtually same as that of normal dry friction. ${ }^{5)}$ On the other hand, the coefficients of friction between $20 \% \mathrm{Cr}$ alloys and $\mathrm{S} 45 \mathrm{C}$ are abnormally large. These results suggest that severe adhesion took place during rubbing in liq. $\mathrm{N}_{2}$. This consideration is supported by the weight gain of $\mathrm{S} 45 \mathrm{C}$ specimens.

Figure 2 shows the wear curves for $20 \% \mathrm{Cr}-(\mathrm{Fe}$, Co, $\mathrm{Ni}$ ) alloys rubbed in liq. $\mathrm{N}_{2}$ against SUS316 specimens. In these cases, it was found that the weight loss of both the coupled specimens increased in the reverse order of the hardness of $20 \% \mathrm{Cr}$ alloys.

Photograph 1 shows the cross sections perpendicular to the worn surfaces of " $80 \mathrm{~N}$ " and " $20 \mathrm{~N}$ " specimen after tests against S45C under the load of $11.2 \mathrm{kgf}$, showing subsurface voids. The defective layer in the softer alloy " $80 \mathrm{~N}$ " is thicker than that in the harder

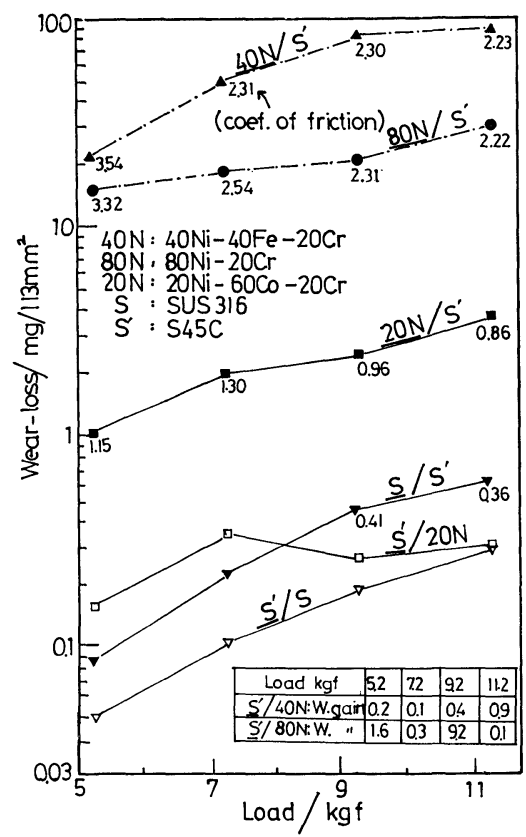

Fig. 1. Wear curves for $20 \% \mathrm{Cr}-(\mathrm{Fe}, \mathrm{Co}, \mathrm{Ni})$ specimens rubbed against $\mathrm{S} 45 \mathrm{C}$ and SUS316 in liq. $\mathrm{N}_{2}$. Coefficient of friction and hardness are also shown. alloy "20N".

Photograph 2 shows typical examples of wear powders collected after tests, showing a round powder of soft " $40 \mathrm{~N}$ " alloy and pile-up platelets of relatively hard " $20 \mathrm{~N}$ " alloy.

Photograph 3 shows the layer of " $40 \mathrm{~N}$ " alloy about $5 \mu \mathrm{m}$ thick adhered on the surface of a $\mathrm{S} 45 \mathrm{C}$ specimen. The rough interface of S45C/“ $40 \mathrm{~N}$ " suggests some degree of wear at the initial stage of rubbing.

Photograph 4 shows the cross section of SUS316 specimen rubbed against " $40 \mathrm{~N}$ " alloy in liq. $\mathrm{N}_{2}$. The deformed layer is about $60 \mu \mathrm{m}$ thick. The " $40 \mathrm{~N}$ " alloy fragment adhered on the surface of SUS316 specimen, and a row of voids can be seen just below the interface. It is considered from these observations that frictional stress was concentrated on the adhered fragments.

When the $\underline{\mathrm{S}} / \mathrm{S}^{\prime}$ curve in Fig. 1 is compared with the $\underline{S} / 40 N$ curve in Fig. 2, it is found that the wear loss of SUS316 (S) against " $40 \mathrm{~N}$ " is about 200 times as large as that of SUS316 (S) against S45C ( $\left.\mathbf{S}^{\prime}\right)$, and that the difference in the coefficient of friction between the two couples is large. Photograph 5 shows all the subsurface defects (voids and cracks) which

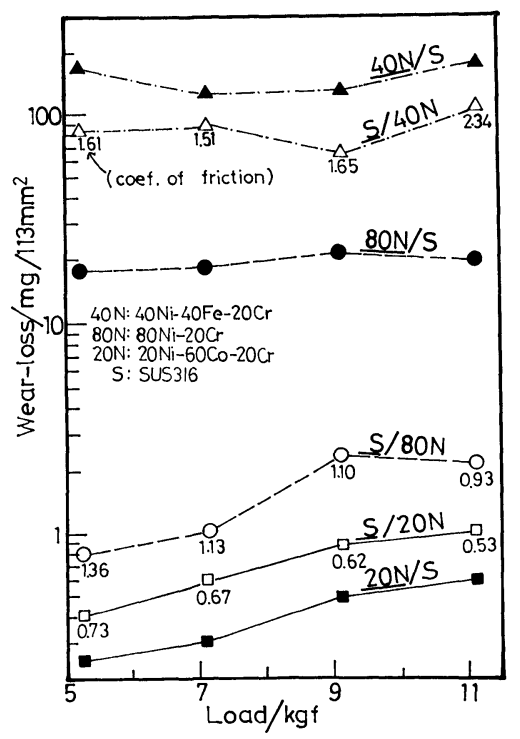

Fig. 2. Wear curves for $20 \% \mathrm{Cr}-(\mathrm{Fe}, \mathrm{Co}, \mathrm{Ni})$ specimens rubbed against SUS316 in liq. $\mathrm{N}_{2}$. Coefficient of friction and hardness are also shown.

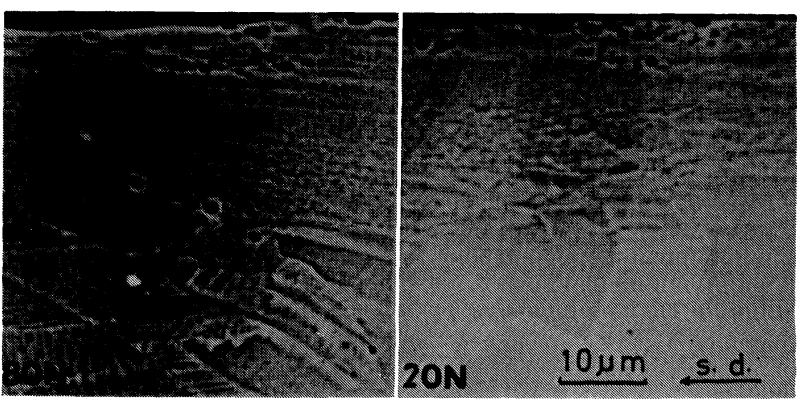

Photo. 1. Cross sections of " $80 \mathrm{~N}$ " and " $20 \mathrm{~N}$ " specimens rubbed against $\mathrm{S} 45 \mathrm{C}$ specimens in liq. $\mathrm{N}_{2}$ under the load of $11.2 \mathrm{kgf}$. 


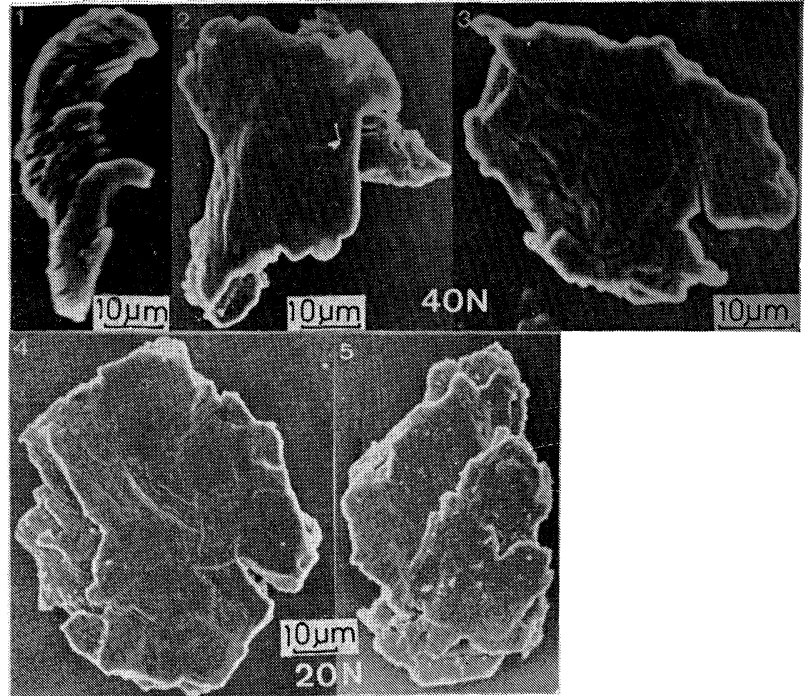

Photo. 2. Wear particles of " $40 \mathrm{~N}$ " and " $20 \mathrm{~N}$ " specimens rubbed against $\mathrm{S} 45 \mathrm{C}$ specimens in liq. $\mathrm{N}_{2}$ under the load of $11.2 \mathrm{kgf}$.

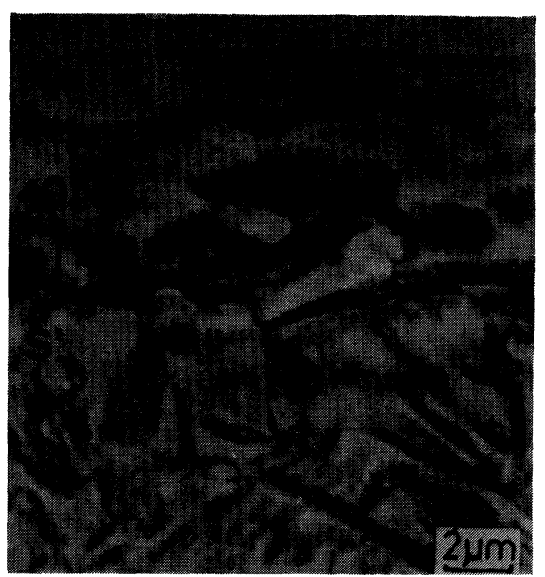

Photo. 3. Cross section of a $\mathrm{S} 45 \mathrm{C}$ specimen, " $\mathrm{S}$ " " rubbed against " $40 \mathrm{~N}$ ", showing adhered layer of " $40 \mathrm{~N}$ ".

can be found in the distance of $1.36 \mathrm{~mm}$ inside the SUS316 specimen rubbed against " $40 \mathrm{~N}$ ". The number of defects is 71 , the total length of defects is 1.53 $\mathrm{mm}$ and the defective zone is about $10 \mu \mathrm{m}$ thick. Photograph 6 shows similar photographs for the SUS 316 specimen rubbed against S45C. The number of defects is 21 , the total length of defects is $0.6 \mathrm{~mm}$ and the defective zone is about $3 \mu \mathrm{m}$ thick. It is concluded from these results that the role of subsurface void formation on the wear is very important. ${ }^{4)}$

As pointed out in the previous paper, ${ }^{11}$ the temperature at the contact surface on rubbing is kept below $0{ }^{\circ} \mathrm{C}$ in liq. $\mathrm{N}_{2}$. It is well known that the coefficient of friction between clean metal surfaces is abnormally large in ultra-high vacuum. ${ }^{6)}$ From these facts, it is considered that the adhesive wear takes place very easily even at subzero temperature, if the atmosphere is sealed from oxidation. In order to ascertain this consideration, wear tests were carried out in liq. $\mathrm{O}_{2}$. The results are shown in Fig. 3. In comparison with the data shown in Figs. 1 and 3, it is clear that the coefficient of friction was decreased

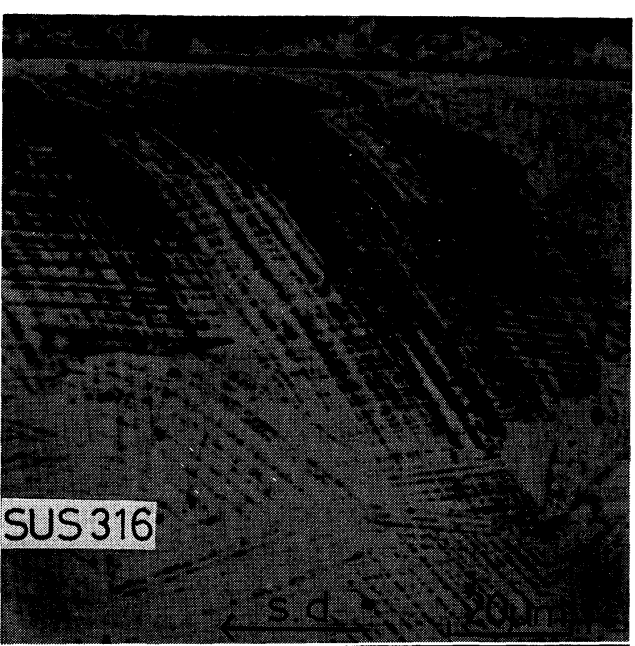

LON

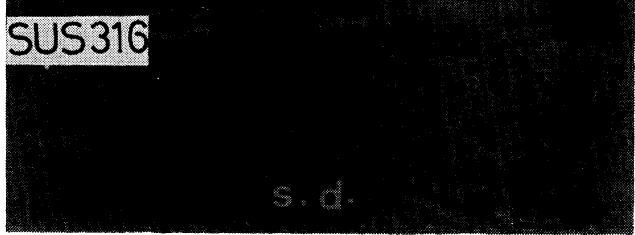

Photo. 4. Gross section of a SUS316 specimen rubbed against " $40 \mathrm{~N}$ ", showing the deformation zone and subsurface voids under an adhered fragment of " $40 \mathrm{~N}$ ".

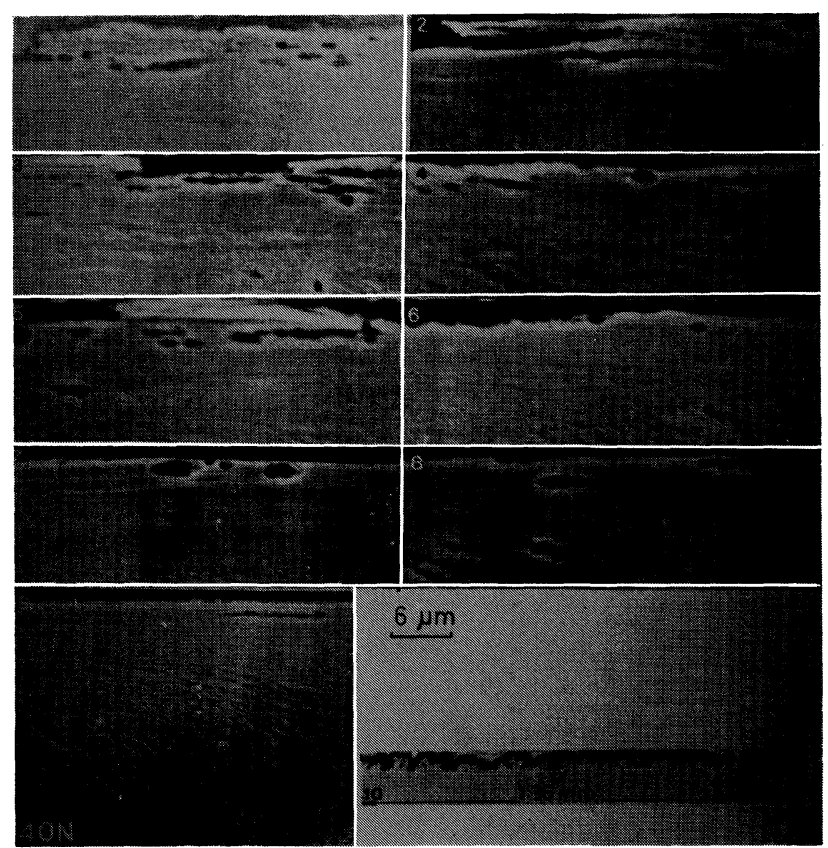

Photo. 5. SEM photographs showing subsurface voids found in the distance of $1.36 \mathrm{~mm}$ of the cross section of a SUS316 specimen rubbed against " $40 \mathrm{~N}$ " in liq. $\mathrm{N}_{2}$ under the load of $11.2 \mathrm{kgf}$.

and adhesion was suppressed by changing the coolant from liq. $\mathrm{N}_{2}$ to $\mathrm{O}_{2}$. However, it is interesting to note that the weight loss of $20 \% \mathrm{Cr}$ alloys did not change appreciably. Photograph 7 shows the worn surfaces of " $40 \mathrm{~N}$ ", " $80 \mathrm{~N}$ " and " $20 \mathrm{~N}$ " specimens rubbed in liq. $\mathrm{N}_{2}$ (upper three) and in liq. $\mathrm{O}_{2}$ (lower two). 


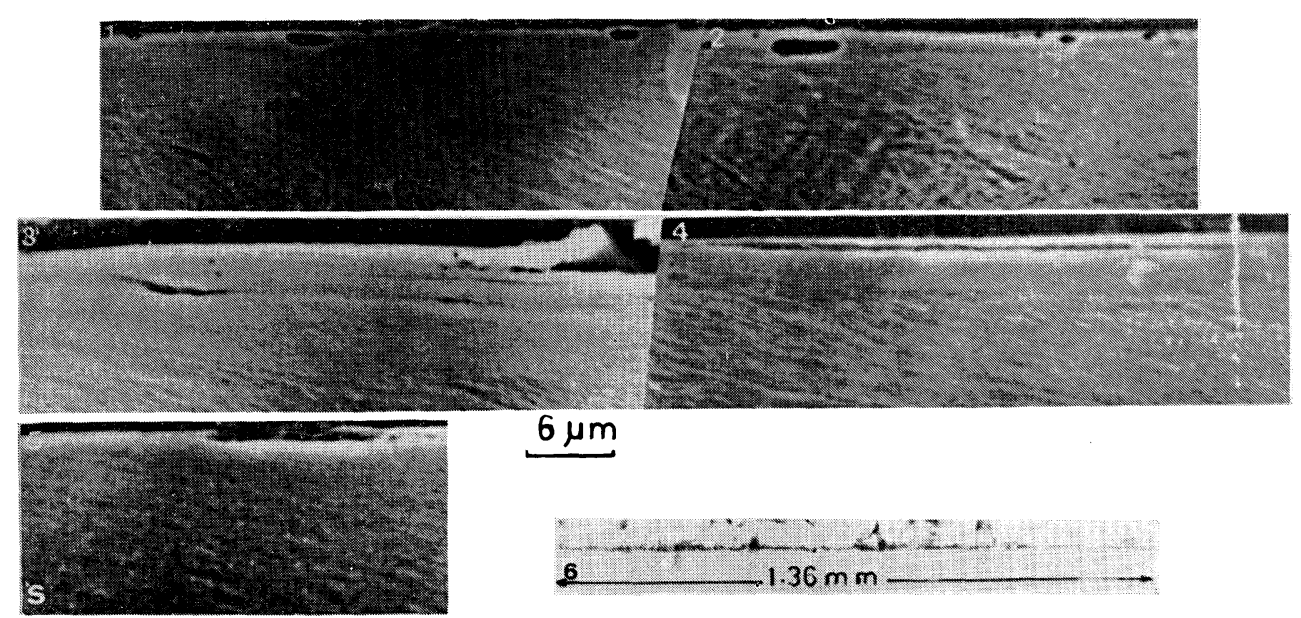

Photo. 6. SEM photographs showing subsurface voids found in the distance of $1.36 \mathrm{~mm}$ of a SUS316 specimen rubbed against a S45C specimen in liq. $\mathrm{N}_{2}$ under the load of $11.2 \mathrm{kgf}$.

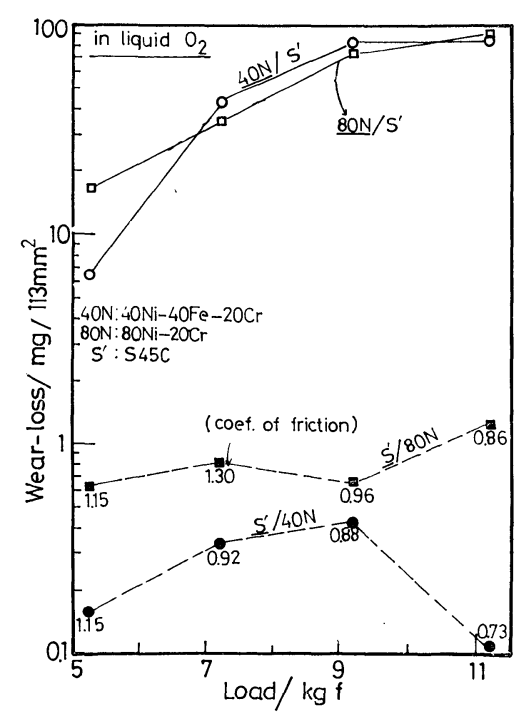

Fig. 3. Wear-loss of " $40 \mathrm{~N}$ " and " $80 \mathrm{~N}$ " alloys against $\mathrm{S} 45 \mathrm{C}$ rubbed in liq. $\mathrm{O}_{2}$. Coefficients of friction are also shown.

The surface of soft " $40 \mathrm{~N}$ " specimen rubbed in liq. $\mathrm{N}_{2}$ (upper left) shows a typical morphology for an adhesively worn surface, that is, fluidal relief. The surface of relatively hard " $20 \mathrm{~N}$ " specimen rubbed in liq. $\mathrm{N}_{2}$ (upper right) shows many abrasive scratches and delaminations. The worn surfaces of " $40 \mathrm{~N}$ " and " $80 \mathrm{~N}$ " specimens rubbed in liq. $\mathrm{O}_{2}$ show delaminations and abrasive scratches. These morphologies suggest that the wear in liquidized gases does not proceed by a unique mechanism, but the plural mechanisms, such as abrasive, adhesive and delamination $^{4,7)}$ mechanisms, are concerned. Because contribution of each mechanism on wearing changes with the condition, sometimes the wearing behaviour is very complicated.

In the next place, it will be described the results of wear tests using age-hardenable alloys, that is, Nimonic 80A ("N8") and Nimonic 100 ("N1") alloys subjected to quenching $(Q)$ and age-hardening (A).

Figure 4 shows the wear curves for "N8" and

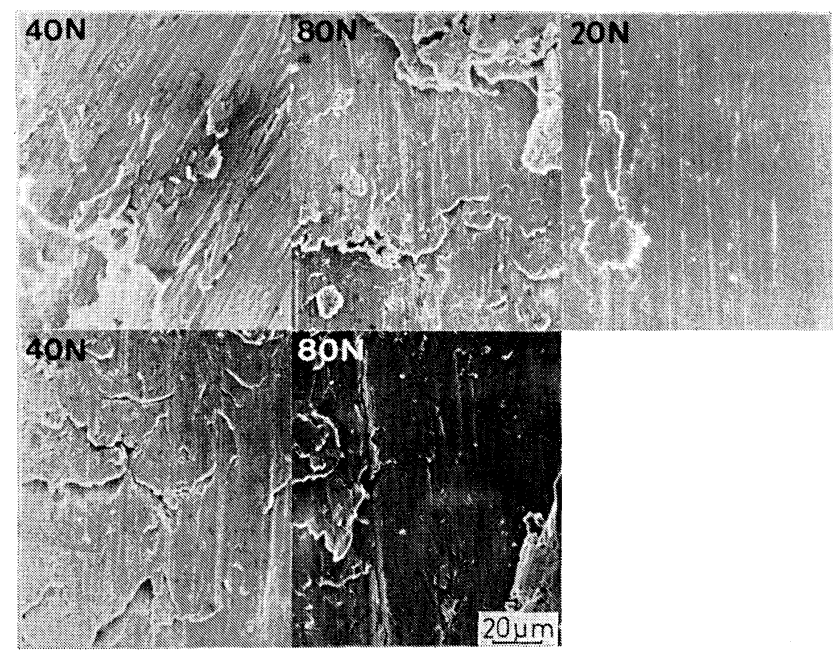

Photo. 7. SEM photographs of worn surfaces of " $40 \mathrm{~N}$ ", " $80 \mathrm{~N}$ " and " $20 \mathrm{~N}$ " specimens rubbed with $\mathrm{S} 45 \mathrm{C}$ under the load of $11.2 \mathrm{kgf}$ in liq. $\mathrm{N}_{2}$ (upper three) and in liq. $\mathrm{O}_{2}$ (lower two).

" $\mathrm{N} 1$ " specimens rubbed in liq. $\mathrm{N}_{2}$ against $\mathrm{S} 45 \mathrm{C}$. The wear loss of the harder alloy, "N1" was less than that of the softer alloy, "N8". The wear-resistances of these alloys were increased by age-hardening. In these alloys without large sources for wearvoids, the void formation may be prevented by age hardening. However the alloys containing sources such as A286 and S816 alloys used in the previous work, ${ }^{2)}$ the propagation velocity of wear cracks during rubbing was accerelated by age hardening due to lowering of the fracture toughness. ${ }^{4,7,8}$

Figure 5 shows the wear curves for "N8" and "N1" specimens rubbed in liq. $\mathrm{N}_{2}$ against SUS316. As shown in this figure, age-hardened "N8" and "N1" alloys are harder than SUS316, and the weights of "N8" and "N1" specimens were increased after wear tests, except "N8" loaded over $9.2 \mathrm{kgf}$. Photograph 8 shows the delamination of an "N8" specimen (left) and SUS316 layer adhered on an "N1" specimen (right). It is noteworthy that the leading mechanism for wear abruptly changed with 


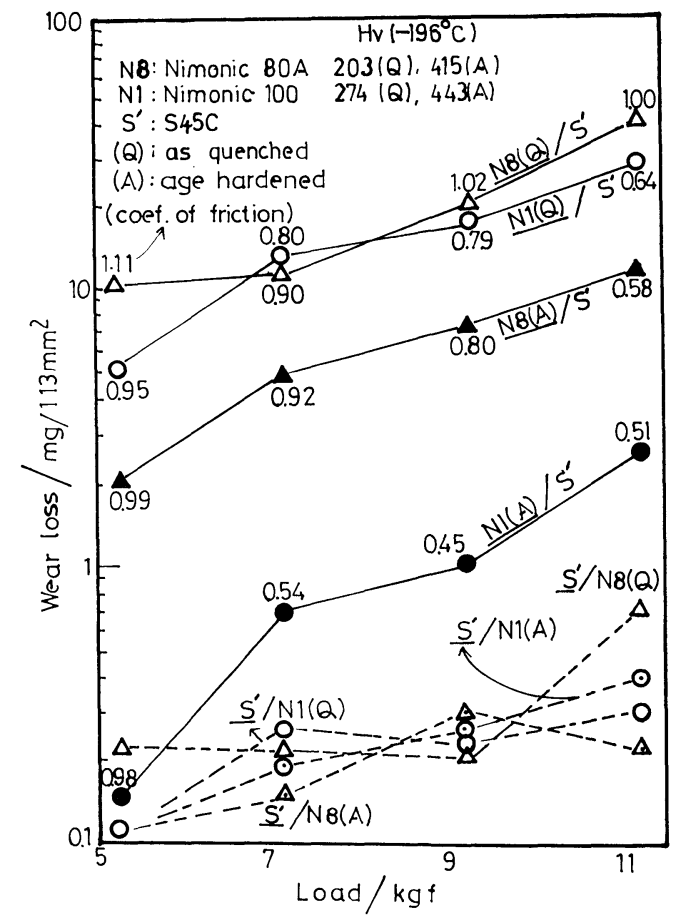

Fig. 4. Wear curves for "N8" and "N1" specimens rubbed against S45C in liq. $\mathrm{N}_{2}$. Coefficients of friction and hardness are also shown.

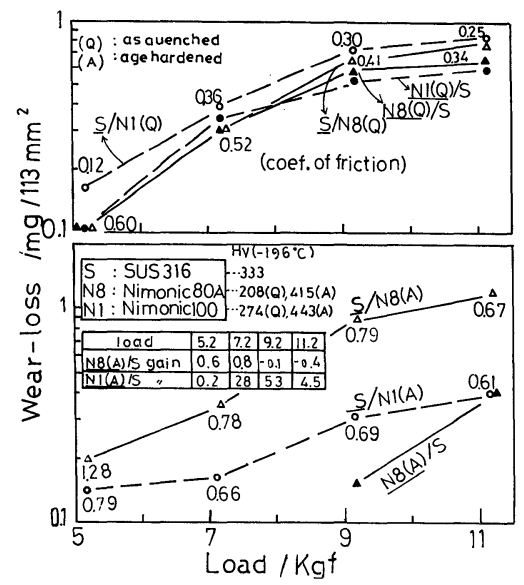

Fig. 5. Wear curves for "N8" and "N1" alloys rubbed against SUS316 in liq. $\mathrm{N}_{2}$. Coefficients of friction and hardness are also shown.

variation of hardness at $\Delta \mathrm{Hv} 28$.

In the following part, the experimental results for hard and brittle martensitic steels will be described.

Figures 6 and 7 show the wear curves for low-Cr steels and the companions, $\mathrm{S} 45 \mathrm{C}$ steels rubbed together at R.T. and in liq. $\mathrm{N}_{2}$. The worn surfaces tested at R.T. in air were coloured brown by oxidation. As shown in Fig. 6, the coefficient of friction in air at R.T. is larger than that in liq. $\mathrm{N}_{2}$, whereas the oxide film suppresses adhesive wear. This fact suggests that liq. $\mathrm{N}_{2}$ acts as lubricant. In spite of the similar hardness, the wear loss of "TX-8M" specimens is larger than those of other low-Cr steels with dispersed carbides. However, the difference in wearresistance among three steels with dispersed carbide is not so distinct. The wear loss of S45C having

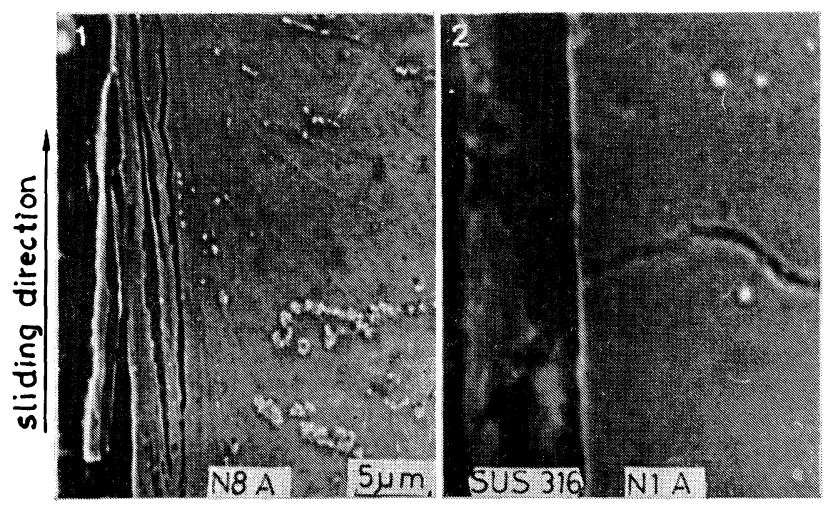

Photo. 8. Corss sections of aged "N8" (left) and "N1" (right) specimens rubbed against SUS316 in liq. $\mathrm{N}_{2}$ under the load of $11.2 \mathrm{kgf}$, showing delamination (left) and adhered layer (right).

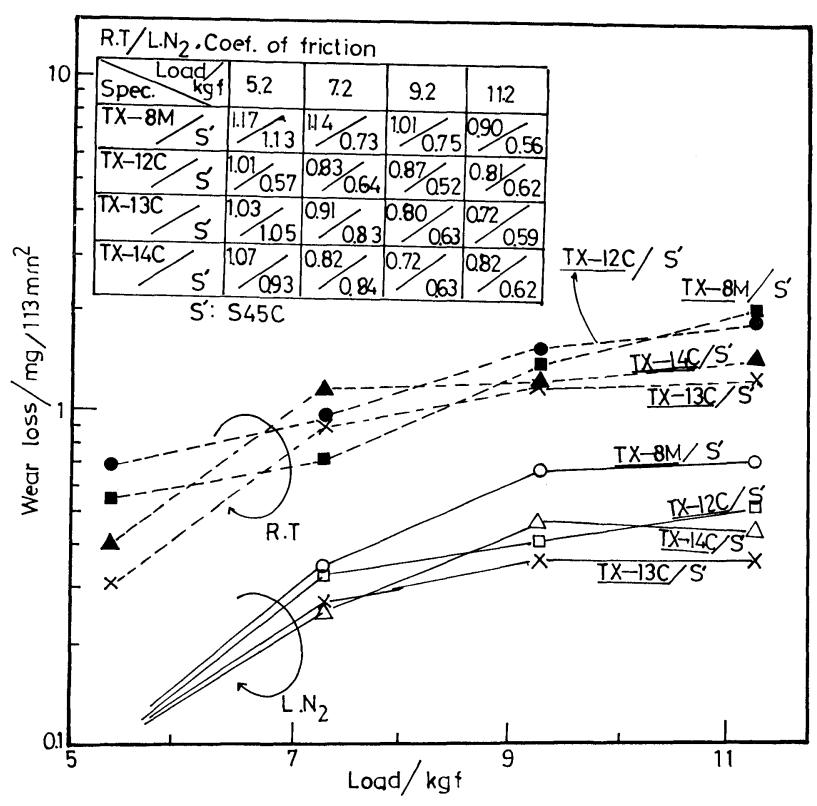

Fig. 6. Wear curves for low-Cr martensitic steels against $\mathrm{S} 45 \mathrm{C}$ steel at $R . T$. and in liq. $\mathrm{N}_{2}$. Coefficients of friction are also shown.

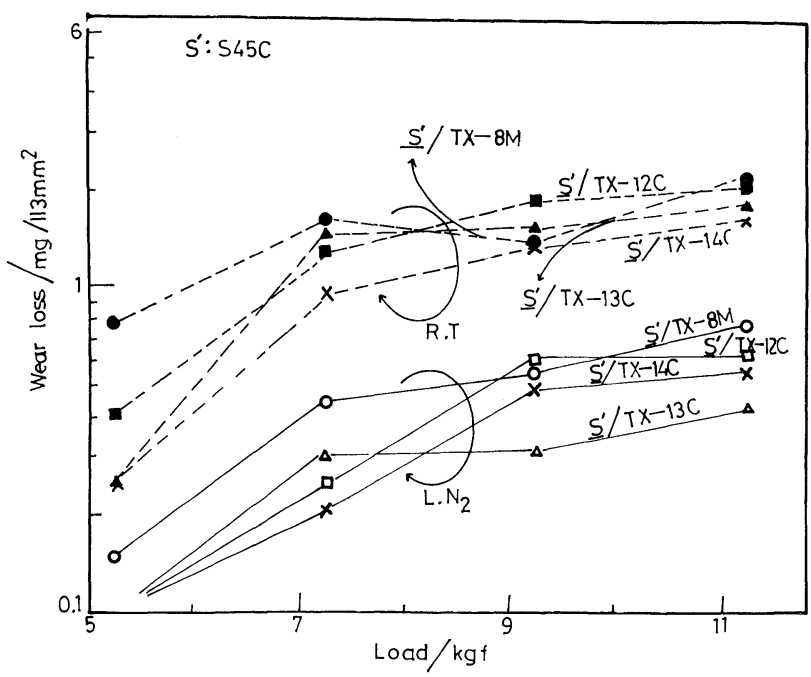

Fig. 7. Wear curves for $\mathrm{S} 45 \mathrm{C}$ steels against low-Cr martensitic steels at R.T. and in liq. $\mathrm{N}_{2}$. 
similar hardness is not much different from that of the companion.

Figure 8 shows the wear curves for low-Cr steels and their companions, SUS316 steels rubbed in liq. $\mathrm{N}_{2}$. The "TX-8M" and "TX-14G" specimens showed weight-gain by adhesion of the soft companion, SUS316.

Photograph 9 shows the optical microphotographs of low-Cr steels. The martensite of "TX-8M" is carbide-free and has rough structure. This rough structure seems to affect the relatively poor resistance of wear of " TX-8M" specimens.

Photograph 10 shows the worn surfaces of "TX-
$14 \mathrm{C}$ " and the companion, S45C specimens rubbed in liq. $\mathrm{N}_{2}$, showing typical abrasive scratches. It is considered that the leading mechanism of wear between the hard and brittle materials is abrasion. In this case, dispersed carbides contribute to increase the wear-proof on the one hand, but on the other hand, they behave as grinding powder. Therefore, the effect of carbide on rubbing wear is complicated.

Photograph 11 shows the worn surfaces of "TX14C" and the companion, SUS316 specimens. The former (right) shows the surface of adhered SUS316 layer on "TX-14G" and the latter (left) shows abrasive scratches.

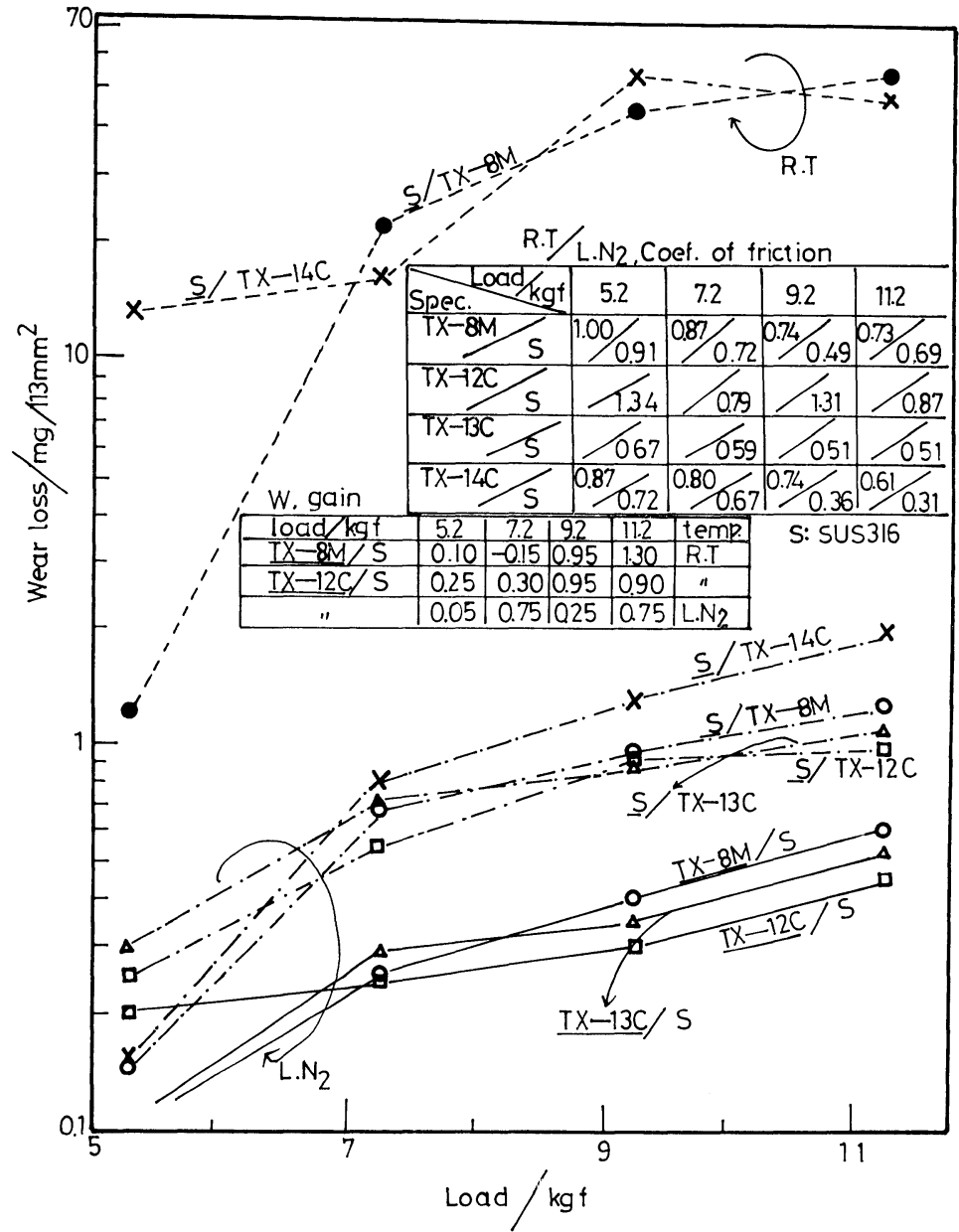

Fig. 8. Wear curves for low-Cr steels against SUS316 steel at R.T. and in liq. $\mathrm{N}_{2}$. Coefficients of friction are also shown.
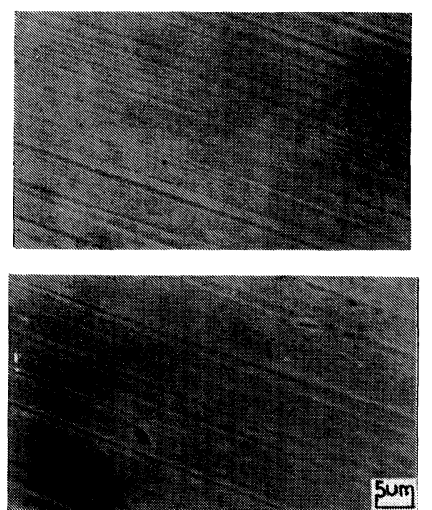

Photo. 10.

SEM photographs of worn surfaces of S45C (upper) and "TX-14G" specimens rubbed under the load of $11.2 \mathrm{kgf}$ in liq. $\mathrm{N}_{2}$ (lower).

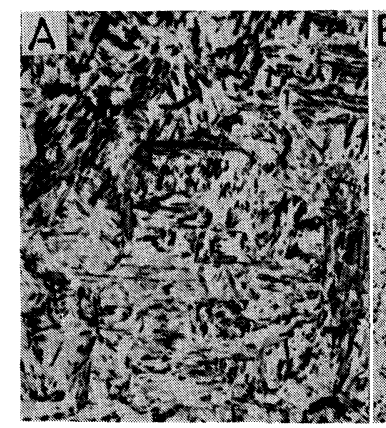

A: $\mathrm{TX}-8 \mathrm{M}$

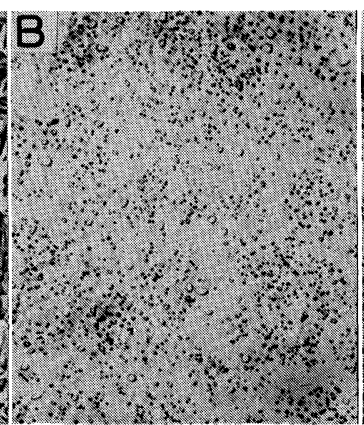

B: $\mathrm{TX}-12 \mathrm{C}$

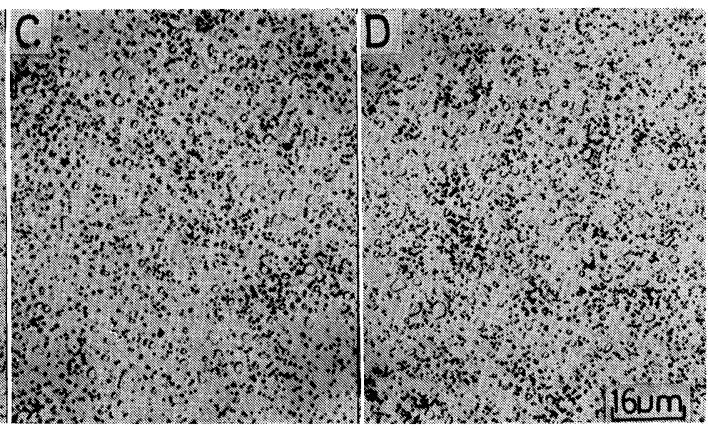

C: TX-13C
D: $\mathrm{TX}-14 \mathrm{C}$

Photo. 9. Microstructures of low-Cr steels tested. 

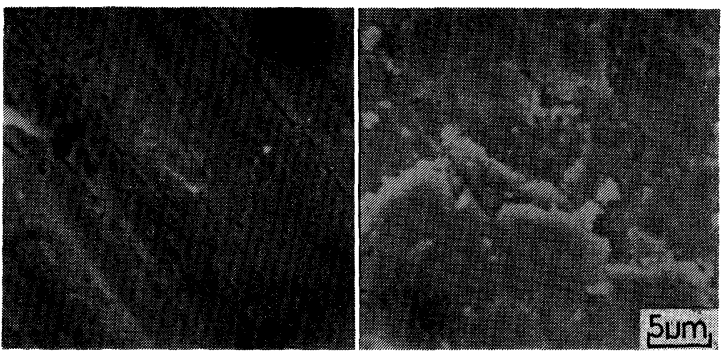

Photo. 11. SEM photographs of worn surfaces of SUS316 (left) and "TX-14C" (right) specimens rubbed together under the load of $11.2 \mathrm{kgf}$ in liq. $\mathrm{N}_{2}$.

Table 6. Rolling contact fatigue life in liq. $\mathrm{N}_{2}$ under the load of $333 \mathrm{kgf}$.

\begin{tabular}{c|cccc}
\hline Specimen & TX-8M & TX-12C & TX-13C & TX-14C \\
\hline Life (cycles) & 175500 & 296700 & 402300 & 450600
\end{tabular}

The rolling contact fatigue lives tested in liq. $\mathrm{N}_{2}$ are shown in Table 6 . The life of martensite was extended by carbide dispersion in the same manner as that at $R . T^{3)}$ In these experiments, the profiles of tracks engraved by rolling SUJ-2 balls on specimens were similar, because the three low-Cr steels have similar hardness. The width was about $0.8 \mathrm{~mm}$ and the depth was about $5 \mu \mathrm{m}$. Assuming the profile to be arc, the Hertz's stress by a ball of $6.3 \mathrm{~mm}$ in diameter put the load of $333 \mathrm{kgf}$ can be calculated as follows ${ }^{9}$; the maximum compression stress is 1776 $\mathrm{kgf} / \mathrm{mm}^{2}$, the major and minor axes of the contact ellipsoid are 0.45 and $0.39 \mathrm{~mm}$. Therefore, the maximum shear stress seems to be induced at the depth of 0.3 to $0.4 \mathrm{~mm}$ from the contact plane. The experimentally obtained depths of flaking on the surfaces of " TX-8M", "TX-12C", "TX-13C" and "TX$14 \mathrm{C}$ " specimens were $0.62,0.55,0.44$ and $0.38 \mathrm{~mm}$, respectively.

Photograph 12 shows examples of cross section of a flaked "TX-14G" specimen and the worn out debris. Photograph 13 shows the flaked surfaces of "TX$8 \mathrm{M}$ " and "TX-14C". These appearances are similar to those of delaminated surfaces as shown in Fig. 7, except abrasive scratches.

\section{Discussion}

The delamination theory of wear was introduced by Suh et al. $., 7,8)$ in order to explain the wear of metals. This theory postulated the following sequence of processes: As subsurface deformation continues by repeated loading transmitted through the contact points of the companion, cracks are nucleated around hard particles, for example, non-metallic inclusions below the surface. The cracks tend to propagate parallel to the surface under the triaxial stresses and finally delaminations take place. This mechanism is very similar to that of the flaking by rolling contact fatigue. ${ }^{9)}$

In the case that the rubbing force is transmitted through adhesive asperities (see Photo. 4), the posi-

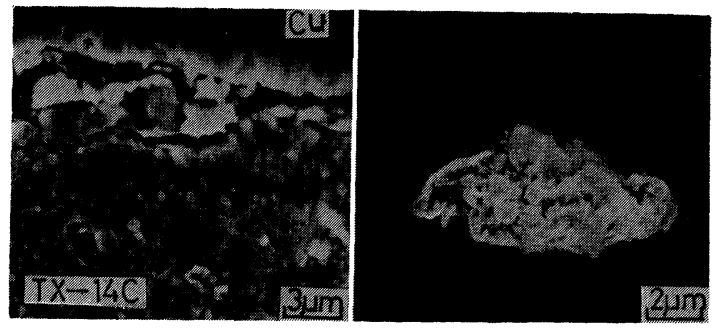

Photo. 12. SEM photographs of the cross section of "TX$14 \mathrm{C}$ " specimen (left) and the debris (right) after rolling contact fatigue test in liq. $\mathrm{N}_{2}$.
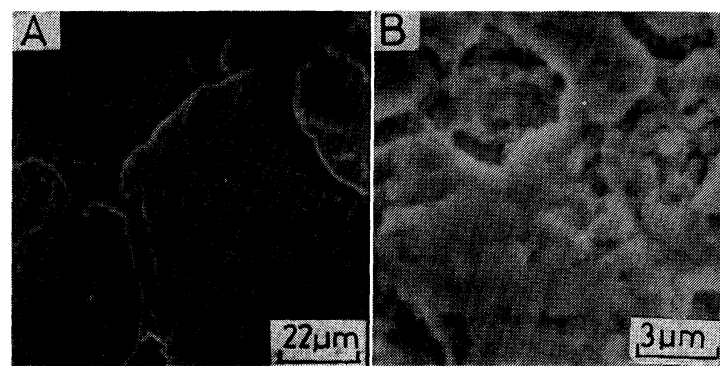

Photo. 13. SEM photographs of flaked surfaces of "TX-8M" (left) and "TX-14G" (right) specimens after tests in liq. $\mathrm{N}_{2}$.

tion of void-nucleation will be in the observable depth as shown in Photos. 4 to 6 . In the case of rubbing between martensitic specimens, the width of contact points should be the order of the width of abrased scratches drawn on the specimen surfaces as shown in Photo. 10, and this is the order of carbide particle size. In such a case, even if delamination takes place in these hard and brittle materials, it will be masked by abrasion.

\section{Conclusions}

The tests of rubbing wear against hardened 0.45 $\%$ C-steel and 316-type austenitic stainless steel were carried out in liq. $\mathrm{N}_{2}$. The results obtained are as follows:

(1) The harder the solid solution alloy is, the smaller the wear-loss is. The softer material adheres easily on the surface of the harder specimen.

(2) Age-hardening increases the wear-proof of the alloy without large sources for wear-voids, in contrast to the previous report ${ }^{3)}$ that if the alloy contains many void-sources such as inclusions, age-hardening decreases the wear-proof.

(3) The combination of martensitic steels results in abrasive wearing. However, it can be suppressed by carbide dispersion, although the effect of carbides on wear-proof is not so distinct.

(4) The rolling contact fatigue life in liq. $\mathrm{N}_{2}$ is increased by carbide dispersion.

(5) In general, it is found that the soft and ductile materials are adhesively worn, that the tough materials are worn by delamination process, and that the hard and brittle materials are abrasively worn. However, in practice, various kinds of processes proceed simultaneously, and contribution of each process de- 
pends on the wearing conditions.

\section{REFERENCES}

1) B. S. Chun and H. Suto: Tetsu-to-Hagané, 68 (1982), 2010.

2) H. Suto and B. S. Chun: Trans. ISIJ, 20 (1980), 555.

3) K. Monma, H. Suto and K. Nakano: J. Japan Inst. Metals, 31 (1967), 1266.

4) J.J. Pamies-Teixira, N. Saka and N. P. Suh: Wear, 44 (1977), 65.
5) E. Rabinowicz: Am. Soc. Lub. Eng. Trans., 14 (1971), 198.

6) Y. Kimura: "Theory and Application of Wear and Lubrication", The 66th and 67th Nishiyama Seminar, ISIJ, (1980), 4.

7) N. P. Suh: Wear, 25 (1973), 111.

8) S. Jahanmir and N. P. Suh: Wear, 44 (1977), 57 \& 87.

9) H. Suto: Materials Testing, Uchida-rokakuho-shinsha, Tokyo, (1976), 146.

K. Ono: Materials Mechanics, Maruzen, Tokyo, (1938), 570. 